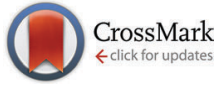

Cite this: J. Mater. Chem. C, 2015, 3, 7925

Received 25th March 2015, Accepted 29th May 2015

DOI: $10.1039 / c 5 t c 00837 a$

www.rsc.org/MaterialsC

\section{Modulation of the ligand-based fluorescence of $3 d$ metal complexes upon spin state change $+\neq$}

\author{
Charles Lochenie, ${ }^{a}$ Kristina G. Wagner, ${ }^{\mathrm{b}}$ Matthias Karg ${ }^{\star b}$ and Birgit Weber ${ }^{{ }^{\mathrm{a}}}$ \\ Two new Schiff base-like ligands bearing a heteroaromatic fluorophore were synthesised and converted \\ into the corresponding $\mathrm{Ni}(॥), \mathrm{Cu}(॥)$ and $\mathrm{Zn}(॥)$ square planar complexes. The $\mathrm{Ni}(॥)$ complexes were studied \\ with regard to a coordination change-induced spin state change upon addition of pyridine in solution. \\ An inverse correlation between the fluorescence properties and the spin state of the metal centre was \\ observed, and investigated with steady state fluorescence and time-resolved spectroscopy.
}

\section{Introduction}

Spin crossover (SCO) complexes are switchable molecules where the change of the spin state can be triggered by a wide range of physical or chemical stimuli such as temperature, pressure, light irradiation or absorption/desorption of guest molecules. This switching process is accompanied by magnetic, optical and structural changes that can be coupled to additional properties (e.g. liquid crystal phase transition). ${ }^{1}$ Due to their high variability with regard to the factors triggering the spin transition and the accompanying changes that can be "read out", SCO complexes are one of the most important molecule-based switchable materials and excellent candidates for technological application., ${ }^{2,3}$ Iron(II) is the most widely used metal centre for the synthesis of SCO complexes. For those complexes wide hysteresis loops around room temperature ${ }^{4}$ - even at nanoscale ${ }^{3,5}$ or photoinduced spin state changes $^{6}$ at high temperatures could already be realised. However, the phenomenon itself is not limited to iron(II) or other $3 \mathrm{~d}^{4-7}$ metal centres with an octahedral coordination sphere. ${ }^{7}$ The coordination induced spin state change of nickel(II) complexes from diamagnetic $(S=0)$ square planar to paramagnetic $(S=1)$ square pyramidal or octahedral coordination sphere shifted recently back into focus. With respect to potential applications for example in the field of smart contrast agents for magnetic resonance imaging, it is of interest to realise ligand systems which allow for light induced switching between these states. Ideally the transitions can be

\footnotetext{
${ }^{a}$ Inorganic Chemistry II, Universität Bayreuth, Universitätsstrasse 30, NW I, 95440 Bayreuth, Germany. E-mail: weber@uni-bayreuth.de

${ }^{b}$ Physical Chemistry I, Universität Bayreuth, Universitätsstrasse 30, NW I, 95440 Bayreuth, Germany. E-mail: matthias.karg@uni-bayreuth.de

$\dagger$ Dedicated to Prof. Manfred Scheer on the occasion of his 60th birthday.

¥ Electronic supplementary information (ESI) available. CCDC 1055605 and 1055606. For ESI and crystallographic data in CIF or other electronic format see DOI: $10.1039 / \mathrm{c} 5$ tc00837a
}

induced at room temperature in solution and on a single molecule level. ${ }^{8}$

The combination of the spin transition with luminescence, if possible in a molecular system, would provide another "readout" feature with a high application potential in the field of drug delivery, biomarkers or thermometry. Several attempts were already reported for the realisation of such bifunctional materials, mostly with iron(II). One possibility to achieve such systems is the synthesis of composite materials such as thin films doped with SCO complexes for electroluminescence, ${ }^{9}$ functionalised SCO-core-luminescence-shell nanoparticles ${ }^{10,11}$ or SCO complexes with fluorescent counter anions. ${ }^{10,12}$ Another possibility is to covalently link the fluorophore to the SCO centre through ligand design. ${ }^{11,13}$ However, this approach is not always successful with respect to a coupling between spin transition and fluorescence. ${ }^{14}$ So far only one example for a nickel(II) based fluorescent molecular thermometer is known, where the emission colour and intensity can be switched through a spin state change. ${ }^{15}$

Here we present a new ligand system that shows a modulation of the fluorescence intensity upon a spin state change. The fluorescence properties of the free ligands, the diamagnetic zinc(II) complexes, the paramagnetic copper(II) complexes and the $S=0 \leftrightarrow S=1$ switchable nickel(II) complexes were investigated with steady-state extinction and fluorescence spectroscopy as well as time-resolved fluorescence spectroscopy.

\section{Results}

\section{Syntheses}

All metal complexes were synthesised in two steps. Starting with the diamines $\mathbf{1}$ and $\mathbf{4}$, firstly a condensation with a ketoenol ether forms the chelate cycles, which then react with metal 

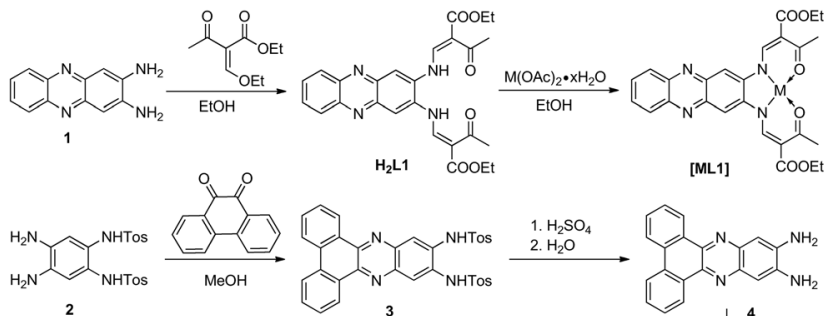

[ML1] COOEt

acetate to give the respective complexes [ML1] and [ML2] $\left(\mathrm{M}=\mathrm{Ni}^{\mathrm{II}}, \mathrm{Cu}^{\mathrm{II}}, \mathrm{Zn}^{\mathrm{II}}\right)$, the counter anionic acetates acting as bases for deprotonation of the ligand. The molecular structures and the synthetic pathway are given in Scheme 1. All complexes were obtained as pure powder with the general formula [ML1] or [ML2]. All ligands and intermediates were characterised with IR, CHN and ${ }^{1} \mathrm{H}-\mathrm{NMR}$. All complexes were characterised with IR, CHN analysis and mass spectrometry.

\section{Crystal structure analysis}

Single crystals suitable for X-ray diffraction analysis of [NiL1] and [CuL1] were obtained from a vapour-vapour slow diffusion setup between a trichloromethane solution of the complex and ethanol. All crystallographic data are given in the ESI:‡ Table S1. While the complex [NiL1] crystallises with the same composition as the bulk material, the structure of compound [CuL1] was determined as [ $\mathbf{C u L 1}(\mathbf{E t O H})] \cdot \mathbf{2} \mathbf{C H C l}_{3}$. Both compounds crystallise in the triclinic space group $P \overline{1}$, and the asymmetric units contain one complex molecule. ORTEP drawings of the asymmetric units are displayed in Fig. 1. The nickel(II) centre in [NiL1] lies in a $\mathrm{N}_{2} \mathrm{O}_{2}$ square planar coordination sphere. Ni-N (1.83 ̊̊) and $\mathrm{Ni}-\mathrm{O}_{\text {eq }}$ $(1.85 \AA)$ bond lengths are in agreement with other complexes with similar coordination sphere. ${ }^{16,17}$ The sum of the angles is with $\Sigma=717^{\circ}$, not far from a perfect square planar coordination sphere $\left(\Sigma=720^{\circ}\right)$. In the case of [CuL1(EtOH)] $2 \mathbf{C H C l}_{3}$, the copper(II) lies in a $\mathrm{N}_{2} \mathrm{O}_{3}$ square pyramidal geometry. $\mathrm{Cu}-\mathrm{N}(1.92 \AA), \mathrm{Cu}-\mathrm{O}_{\text {eq }}$ $(1.92 \AA)$ and $\mathrm{Cu}-\mathrm{O}_{\mathrm{EtOH}}(2.378(5) \AA)$ bond lengths are generally longer than for the nickel complex, due to the different geometry of the coordination sphere and the increase of the covalent radius from $124 \mathrm{pm}(\mathrm{Ni})$ to $132 \mathrm{pm}(\mathrm{Cu})$. Selected bond lengths and angles are presented in Table 1.

The crystal packing of [NiL1] shows the complexes stacked over each other, forming columns along the vector [100]. $\pi-\pi$ interactions between the aromatic rings of the ligand, as well as metal-aromatic interactions between the nickel centre and the chelate rings of neighbouring complexes lead to the formation of the columns in the packing. Illustrations of the packing are shown in Fig. 2, and selected distances of the $\pi-\pi$ interactions are presented in Table 2. The crystal packing of [CuL1(EtOH)]. $\mathbf{2 C H C l}_{3}$ shows a similar stacking than the one observed for [NiL1], with the formation of pairs through $\pi-\pi$ interactions. However, since an ethanol molecule is coordinated axially at the copper centre, no metal-aromatic interactions are observed. Only the aromatic rings of the ligands are interacting, with the copper centres looking in opposing directions in a "head-to-toes" fashion. Furthermore, hydrogen bonds are present between the trichloromethane solvent molecules and the complexes, as well as between the coordinating ethanol and neighbouring complex molecules. Illustrations of the packing are shown in Fig. 3, selected distances and angles of the $\pi$-interactions and of the hydrogen bonds are presented in Tables 2 and 3, respectively.

Powder diffraction patterns of all investigated complexes were measured; the results are displayed in the ESI, $\$$ Fig. S1.
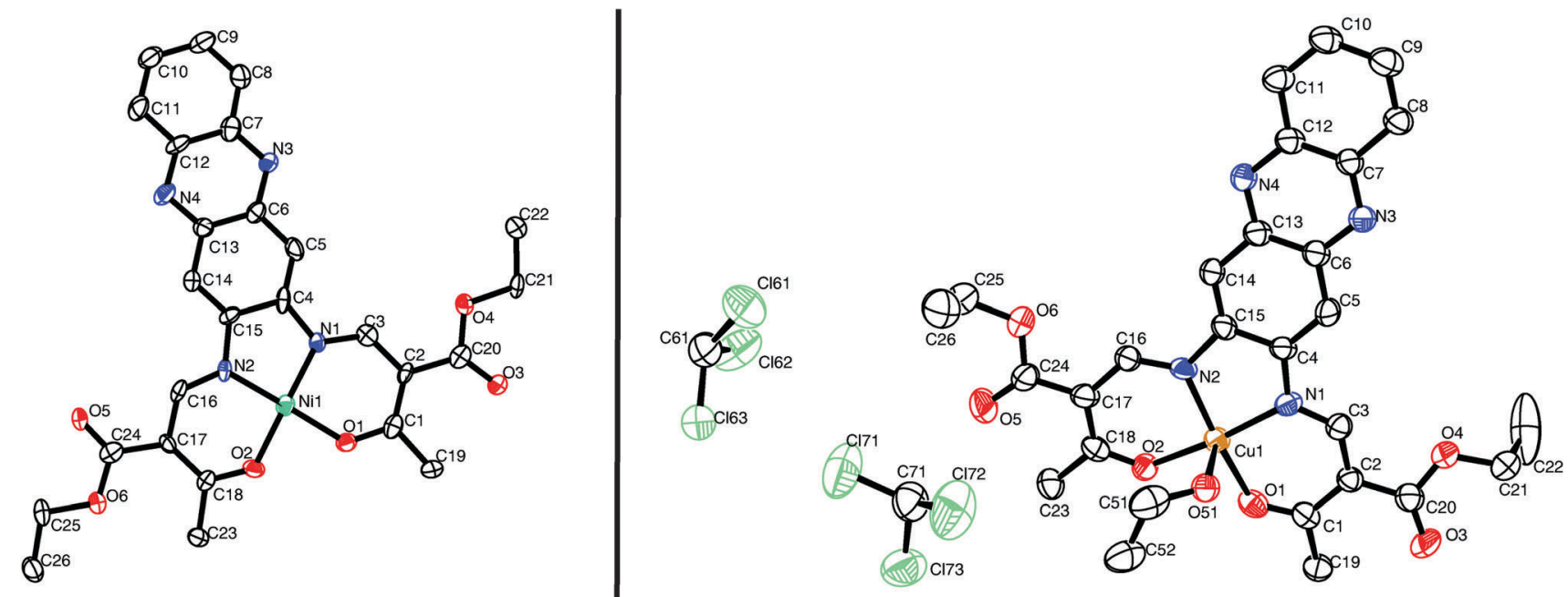

Fig. 1 ORTEP drawing of [NiL1] (left) and [CuL1(EtOH)].2 $\mathrm{CHCl}_{3}$ (right). Thermal ellipsoids are shown at $50 \%$ level. Hydrogen atoms are omitted for clarity. 
Table 1 Selected bond lengths $[\AA ̊]$ and angles $\left[{ }^{\circ}\right]$

\begin{tabular}{|c|c|c|c|c|c|c|c|}
\hline Compound & $\mathrm{M}-\mathrm{N}$ & $\mathrm{M}-\mathrm{O}_{\mathrm{eq}}$ & $\mathrm{M}-\mathrm{O}_{\mathrm{EtOH}}$ & $\mathrm{O}_{\mathrm{eq}}-\mathrm{M}-\mathrm{O}_{\mathrm{eq}}$ & $\mathrm{N}-\mathrm{M}-\mathrm{N}$ & $\mathrm{N}-\mathrm{M}-\mathrm{O}_{\mathrm{eq}}$ & $\mathrm{N} / \mathrm{O}_{\mathrm{eq}}-\mathrm{M}-\mathrm{O}_{\mathrm{EtOH}}$ \\
\hline$[\mathrm{CuL1}(\mathrm{EtOH})] \cdot 2 \mathrm{CHCl}_{3}$ & $\begin{array}{l}1.930(7) \\
1.921(6)\end{array}$ & $\begin{array}{l}1.905(5) \\
1.943(5)\end{array}$ & $2.378(5)$ & $90.8(2)$ & $84.8(3)$ & $\begin{array}{l}92.5(2) \\
90.9(3) \\
171.8(3) \\
171.9(2)\end{array}$ & $\begin{array}{l}91.8(2) \\
92.0(2) \\
95.3(2) \\
96.1(2)\end{array}$ \\
\hline
\end{tabular}
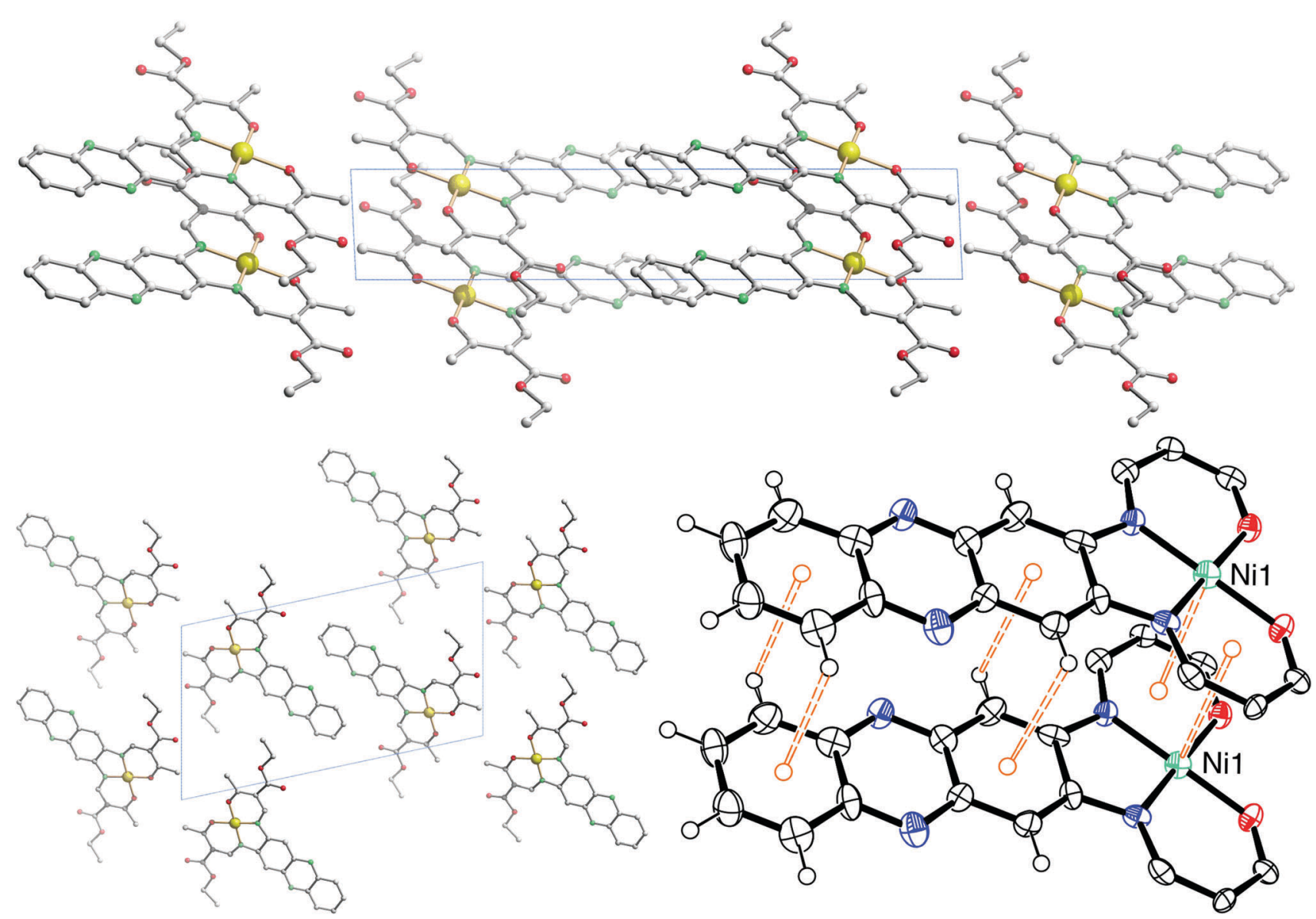

Fig. 2 Illustrations of the crystal packing of [NiL1] along [010] (top) and [100] (bottom left); scheme of the $\pi-\pi$ and $M-\pi$ interactions involved in the packing (bottom right).

The diffraction pattern of the powder sample [CuL1] differs significantly from the calculated one for the single crystals of [CuL1(EtOH)] $\cdot \mathbf{2 C H C l}_{3}$. This is not unexpected since the additional solvent molecules will strongly influence the packing pattern. The diffraction patterns of the three solvent-free complexes of $\mathbf{L 1}$ show only little similarities. The packing of the molecules in the crystals is influenced by the metal centre. In contrast to this the diffraction patterns of [CuL2] and [NiL2] are very similar, for [ $\mathbf{Z n L 2}]$ the differences are more pronounced. For the ligand $\mathbf{L} 2$ with the extended aromatic system the packing of the molecules in the crystal is mostly influenced by the ligand and less by the metal centre.

\section{Steady state spectroscopy}

The optical properties of the ligands and the complexes were studied by extinction and fluorescence spectroscopy. First of all the pure ligand systems were investigated in trichloromethane. Fig. 4A compares the absorbance and emission spectra of $\mathbf{H}_{2} \mathbf{L 1}$ and $\mathbf{H}_{2} \mathbf{L} 2$. The spectral features of both ligands are very similar. Both ligands show a pronounced absorption peak at approx. $440 \mathrm{~nm}$ and emission with a maximum at approx. $470 \mathrm{~nm}$. 
Table 2 Selected distances $[\AA]$ and angles $\left[{ }^{\circ}\right]$ of the $\pi-\pi$ and $M-\pi$ interactions. $\mathrm{Cg}(I)$ is the centroid of the ring number $\mathrm{I}, \alpha$ is the dihedral angle between the rings, $\beta$ is the angle between the vector $\mathrm{Cg}(\mathrm{I}) \rightarrow \mathrm{Cg}(\mathrm{J})$ and the normal to ring $\mathrm{I}, \gamma$ is the angle between the vector $\mathrm{Cg}(\mathrm{I}) \rightarrow \mathrm{Cg}(\mathrm{J})$ and the normal to ring $\mathrm{J}$

\begin{tabular}{|c|c|c|c|c|c|}
\hline $\mathrm{Cg}(\mathrm{I})$ & $\mathrm{Cg}(\mathrm{J})$ & $\mathrm{Cg}-\mathrm{Cg}$ & $\alpha$ & $\beta$ & $\gamma$ \\
\hline \multicolumn{6}{|l|}{ [NiL1] } \\
\hline C4-C5-C6-C13-C14-C15 & $\mathrm{C} 4-\mathrm{C} 5-\mathrm{C} 6-\mathrm{C} 13-\mathrm{C} 14-\mathrm{C} 15^{a}$ & $4.084(3)$ & 0 & 33.42 & 33.42 \\
\hline C4-C5-C6-C13-C14-C15 & $\mathrm{C} 4-\mathrm{C} 5-\mathrm{C} 6-\mathrm{C} 13-\mathrm{C} 14-\mathrm{C} 15^{b}$ & $4.084(3)$ & 0 & 33.42 & 33.42 \\
\hline C6-N3-C7-C12-N4-C13 & $\mathrm{C} 6-\mathrm{N} 3-\mathrm{C} 7-\mathrm{C} 12-\mathrm{N} 4-\mathrm{C} 13^{a}$ & $4.084(3)$ & 0 & 32.92 & 32.92 \\
\hline C6-N3-C7-C12-N4-C13 & $\mathrm{C} 6-\mathrm{N} 3-\mathrm{C} 7-\mathrm{C} 12-\mathrm{N} 4-\mathrm{C} 13^{b}$ & $4.084(3)$ & 0 & 32.92 & 32.92 \\
\hline C7-C8-C9-C10-C11-C12 & $\mathrm{C} 7-\mathrm{C} 8-\mathrm{C} 9-\mathrm{C} 10-\mathrm{C} 11-\mathrm{C} 12^{a}$ & $4.084(4)$ & 0 & 32.65 & 32.65 \\
\hline C7-C8-C9-C10-C11-C12 & $\mathrm{C} 7-\mathrm{C} 8-\mathrm{C} 9-\mathrm{C} 10-\mathrm{C} 11-\mathrm{C} 12^{b}$ & $4.084(4)$ & 0 & 32.65 & 32.65 \\
\hline Ni1-O1-C1-C2-C3-N1 & $\mathrm{Ni}^{b}$ & 3.301 & - & 12.75 & - \\
\hline $\mathrm{Ni1}-\mathrm{O} 2-\mathrm{C} 18-\mathrm{C} 17-\mathrm{C} 16-\mathrm{N} 2$ & $\mathrm{Ni}^{a}$ & 3.258 & - & 11.40 & - \\
\hline \multicolumn{6}{|l|}{$[\mathrm{CuL1}(\mathrm{EtOH})] \cdot 2 \mathrm{CHCl}_{3}$} \\
\hline C4-C5-C6-C13-C14-C15 & $\mathrm{C} 7-\mathrm{C} 8-\mathrm{C} 9-\mathrm{C} 10-\mathrm{C} 11-\mathrm{C} 12^{c}$ & $3.837(5)$ & $1.1(4)$ & 28.66 & 29.54 \\
\hline C6-N3-C7-C12-N4-C13 & $\mathrm{C} 6-\mathrm{N} 3-\mathrm{C} 7-\mathrm{C} 12-\mathrm{N} 4-\mathrm{C} 13^{c}$ & $3.807(5)$ & 0 & 28.68 & 28.68 \\
\hline C7-C8-C9-C10-C11-C12 & $\mathrm{C} 4-\mathrm{C} 5-\mathrm{C} 6-\mathrm{C} 13-\mathrm{C} 14-\mathrm{C} 15^{c}$ & $3.838(5)$ & $1.1(4)$ & 29.54 & 28.66 \\
\hline
\end{tabular}

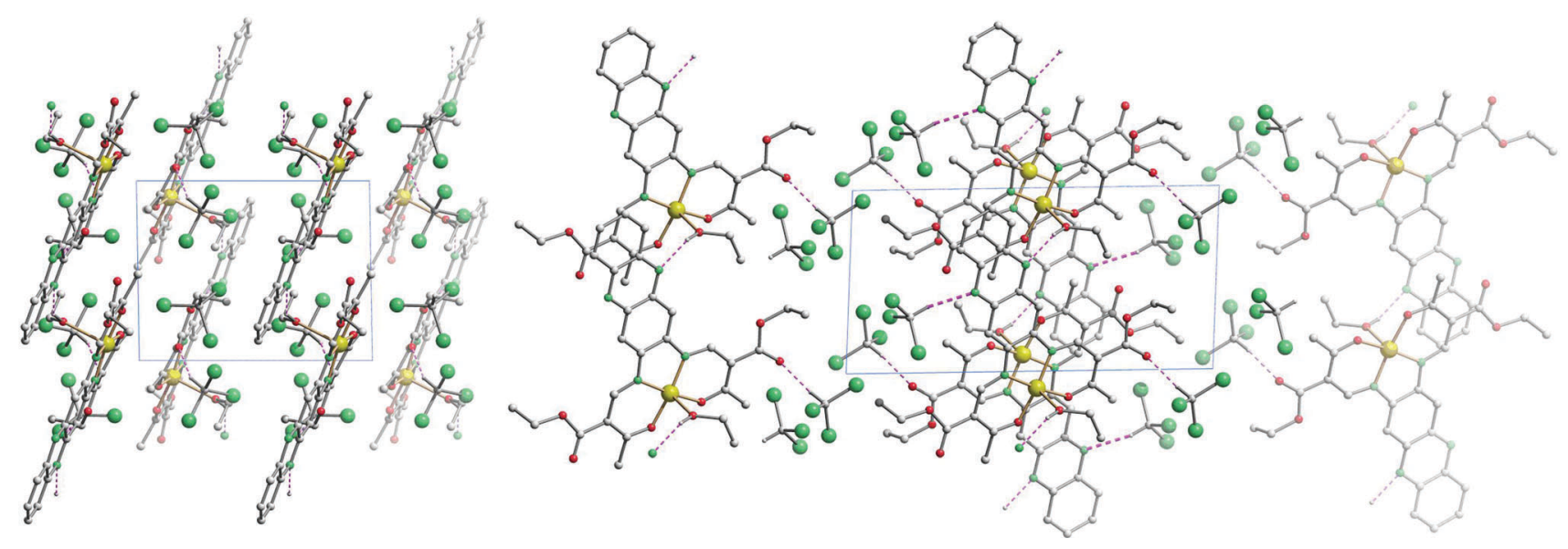

Fig. 3 Illustrations of the crystal packing of [CuL1(EtOH)].2 $\mathrm{CHCl}_{3}$ along [001] (left) and along [010] (right).

Furthermore the absorption peaks show a weak shoulder at lower wavelength, as well as a weak shoulder in the emission spectra at higher wavelength as compared to the peak maximum. These shoulders can be attributed to the equilibrium between imino-enol/keto-enamine tautomers of the ligands in solution. ${ }^{17,18}$

The spectral analyses of the metal complexes ( $\mathrm{Cu}$ and $\mathrm{Zn})$ are shown in Fig. 4B-D. In order to investigate the influence of the spin state on the absorption and fluorescence, spectra of the complexes were measured in trichloromethane and pyridine. Fig. 4B compares the absorbance spectra for the $\mathrm{Cu}$ (II) complexes [CuL1] and [CuL2]. Comparing the spectra measured in trichloromethane similar absorption spectra are observed with the same number of bands. In contrast to this the absorption peaks are redshifted when pyridine is used as solvent (solvatochromism). In case of [CuL2], a weak band appears at $585 \mathrm{~nm}$ in the pyridine solution, that can be attributed to $\mathrm{d}-\mathrm{d}$ transitions by comparison with similar complexes. ${ }^{17}$ In agreement with many examples for fluorophores in literature, fluorescence was not observed for the copper complexes indicating strong quenching due to the presence of the metal centre. ${ }^{19,20}$
The absorption spectra of the zinc(II) complexes [ZnL1] in trichloromethane and pyridine shown in Fig. 4C resemble the spectra of the pure ligand systems. In addition almost no difference in band position and the number of bands is observed comparing the spectra in the two solvents. In contrast to this the complex emission is significantly influenced by changing the solvent from trichloromethane to pyridine. In trichloromethane the emission maximum is at $473 \mathrm{~nm}$, whereas the emission shifts to $560 \mathrm{~nm}$ in pyridine. The absorption spectrum of [ZnL2] in trichloromethane resembles also the spectrum of the corresponding ligand, however changes in the number of bands and their position appear in pyridine solution. The emission spectrum also displays a red-shift as observed for sample [ZnL1], but with a smaller difference between trichloromethane solution $\left(\lambda_{\mathrm{em}}=475 \mathrm{~nm}\right)$ and pyridine solution $\left(\lambda_{\mathrm{em}}=529 \mathrm{~nm}\right)$. The optical properties of the nickel(II) complexes [NiL1] and [NiL2] were investigated by adding a pyridine solution of the complex into an equimolar trichloromethane solution of the same complex, as the nickel centre undergoes a spin state change upon coordination change (see Scheme 2). ${ }^{7,15}$ Respective absorbance and emission spectra are 
Table 3 Selected distances $[\AA]$ and angles $\left[{ }^{\circ}\right]$ of the hydrogen bonds present in the packing of [CuL1(EtOH)].2 $\mathrm{CHCl}_{3}$

\begin{tabular}{lllll}
\hline $\mathrm{D}-\mathrm{H} \cdots \mathrm{A}$ & $\mathrm{D}-\mathrm{H}$ & $\mathrm{H} \cdots \mathrm{A}$ & $\mathrm{D} \cdots \mathrm{A}$ & $\mathrm{D}-\mathrm{H} \cdots \mathrm{A}$ \\
\hline $\mathrm{O} 51-\mathrm{H} 51 \cdots \mathrm{N} 4^{a}$ & 0.84 & 2.11 & $2.820(8)$ & 142 \\
$\mathrm{C}^{a} 1-\mathrm{H} 61 \cdots \mathrm{N} 3^{b}$ & 1.00 & 2.35 & $3.297(14)$ & 158 \\
$\mathrm{C} 71-\mathrm{H} 71 \cdots \mathrm{O} 5$ & 1.00 & 2.07 & $3.007(14)$ & 155
\end{tabular}

$a=-1+x, y, z ; b=x, y, 1+z$.

shown in Fig. 5. The trichloromethane solutions of the nickel complexes show three absorption bands at 365, 414, and $448 \mathrm{~nm}$ for [NiL1], and at 412, 440, and $465 \mathrm{~nm}$ for [NiL2]. Upon progressive coordination of pyridine molecules onto the nickel centre, the absorption spectra dramatically change. In the case of [NiL1], the bands at 414 and $448 \mathrm{~nm}$ tend to disappear whereas the band at $365 \mathrm{~nm}$ increases and a new band at $493 \mathrm{~nm}$ appears. For the sample [NiL2] the intensity of the bands at 412 and $440 \mathrm{~nm}$ decreases and two new bands at 375 and $500 \mathrm{~nm}$ appear. The drastic changes in the absorbance spectra of the nickel complexes confirm the change of geometry and by this the spin state upon coordination with pyridine. The spin state change also affects the fluorescence properties of the complexes (Fig. 5B and D). As pyridine is added to the complex [NiL1], its emission band at $478 \mathrm{~nm}$ progressively red-shifts and its intensity dramatically

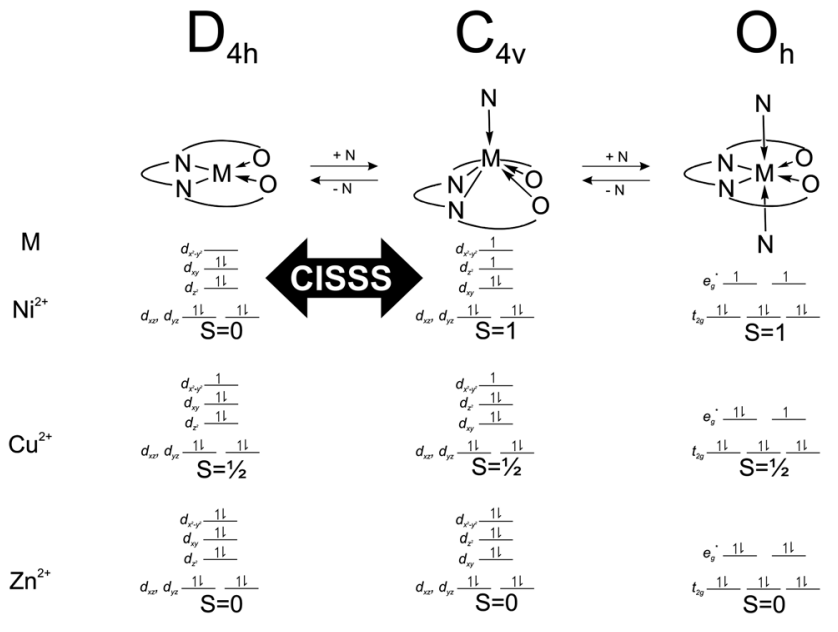

Scheme 2 Electronic configuration, spin number and geometry of the different complexes in equilibrium in solution upon addition of pyridine.

decreases. The redshift seems in good agreement with the emergence of a new band at higher wavelength $(493 \mathrm{~nm})$ in the absorption spectrum upon addition of pyridine. For the complex [NiL2], a completely different effect is observed. Upon addition of the first equivalents of pyridine, the emission band at $491 \mathrm{~nm}$ is
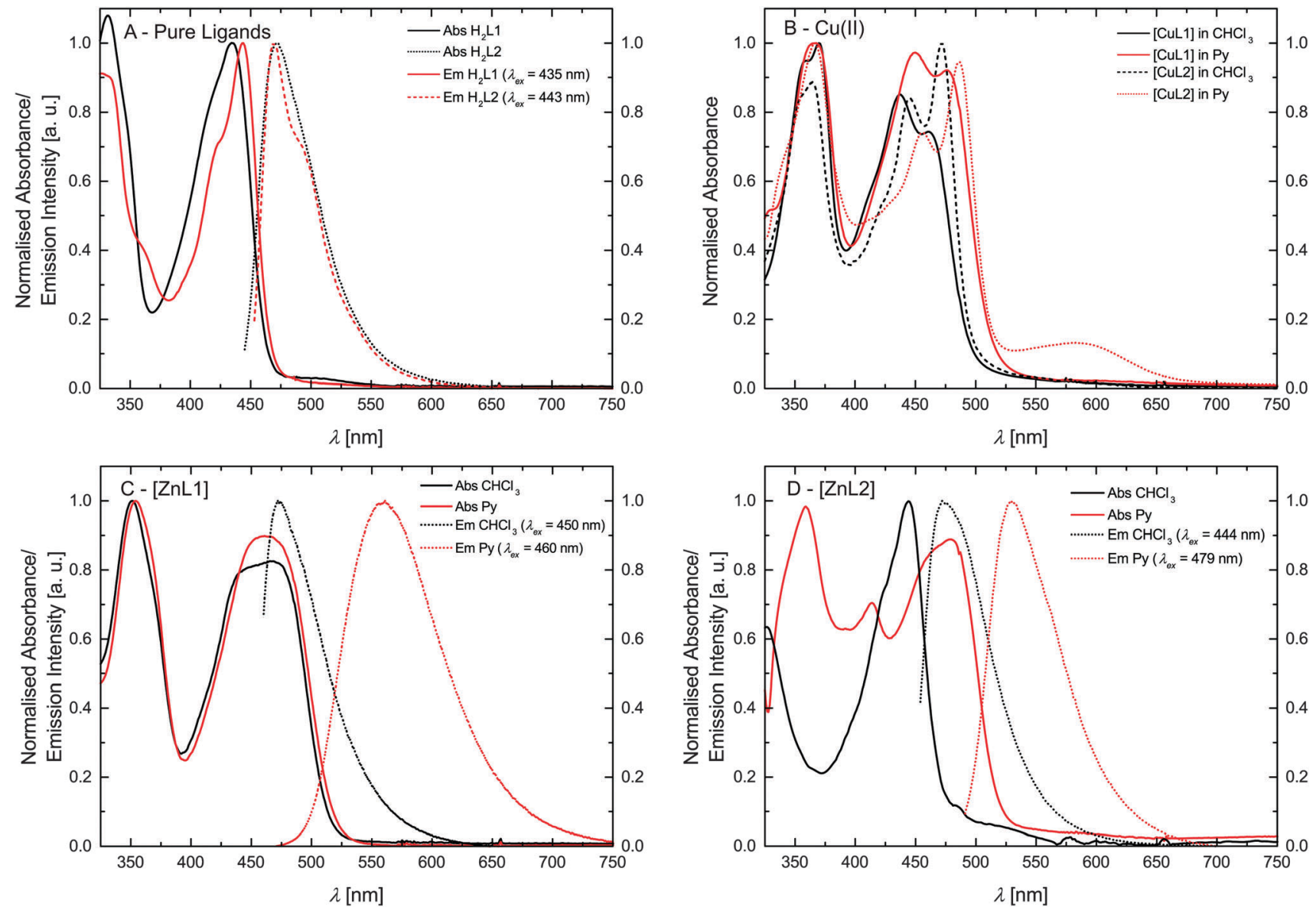

Fig. 4 Absorption and emission spectra. (A) Pure ligands. (B) Cu(I) complexes. (C and D) Zn(॥) complexes. 

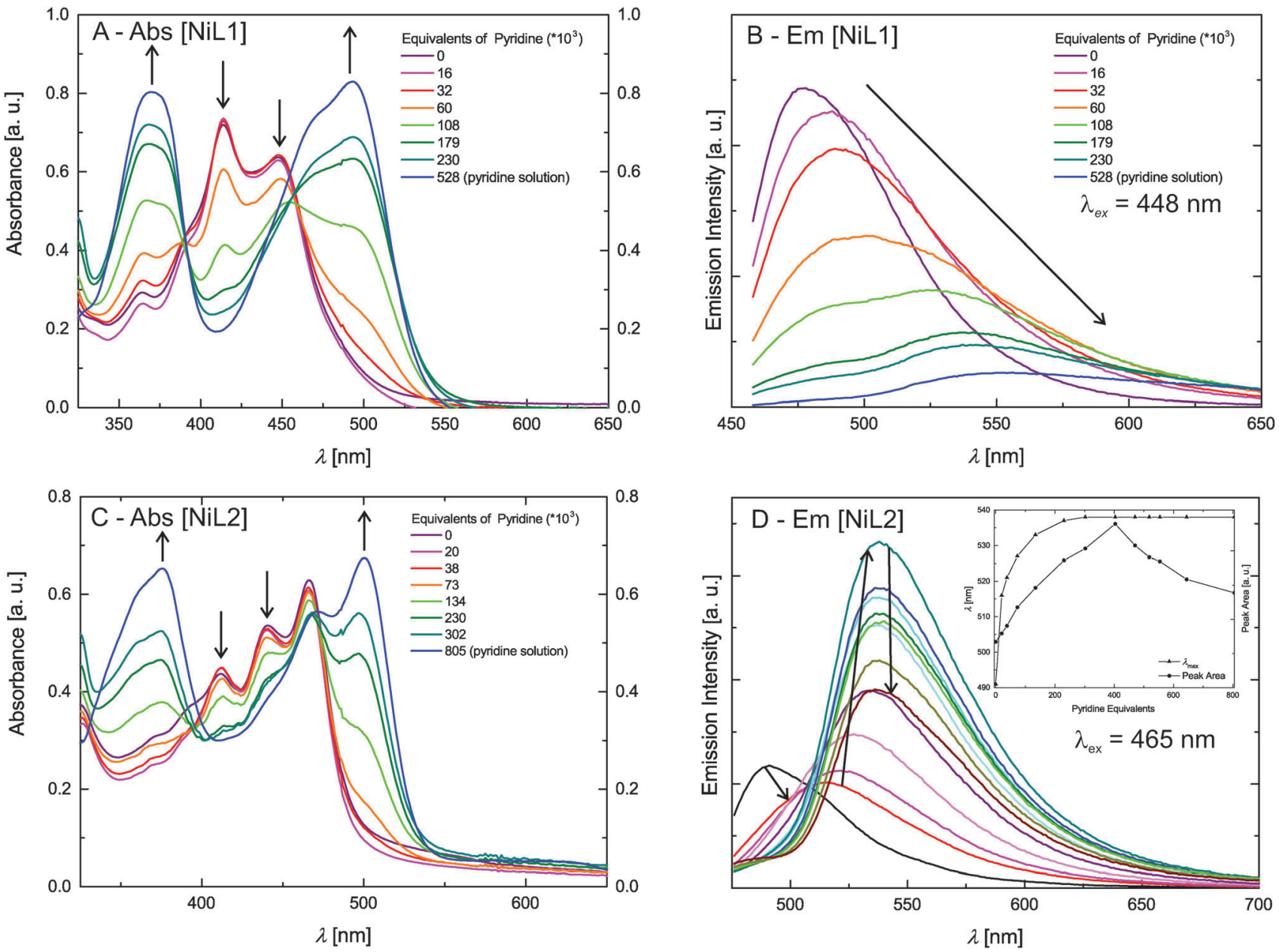

Fig. 5 Absorption and steady state fluorescence measurements of the Ni(I) complexes. The inset in D gives the integrated peak area and $\lambda_{\text {max }}$ as guide for the reading of the graph.

shifted to $538 \mathrm{~nm}$, and its intensity increases until $\approx 400$ equivalents of pyridine are added. Further addition of pyridine leads to a decrease of the emission intensity.

The reversibility of the coordination of the pyridine molecules was investigated with absorption spectroscopy. First, a pyridine solution of the [NiL1] complex was progressively added to an equimolar trichloromethane solution of the complex. In the next step, the pyridine concentration of this solution was reduced by addition of the original trichloromethane solution. The intensity of the characteristic absorption bands of the complex in pyridine $(\lambda=365 \mathrm{~nm})$ and in trichloromethane $(\lambda=414 \mathrm{~nm})$ varies in agreement with a reversible coordination of the pyridine molecules to the metal centre. Fig. S2 in the ESI illustrates those results. The absorption spectra of the fluorescent $\mathrm{Ni}(\mathrm{II})$ and $\mathrm{Zn}$ (II) complexes were also measured in trichloromethane solutions containing triethylamine $\left(\mathrm{Et}_{3} \mathrm{~N}\right)$ as non-coordinating base, or formic acid $(\mathrm{HCOOH})$, in order to rule out possible effects due to (de)protonation of the complexes. The corresponding UV-vis spectra are presented in the ESI: $\neq$ Fig. S3. The spectra show that in all cases, no significant changes are observed for the $\mathrm{CHCl}_{3}-\mathrm{Et}_{3} \mathrm{~N}$ solutions, proving that the changes observed for the pyridine addition are due to coordination of pyridine at the axial positions of the nickel centre. Spectra of the complexes in $\mathrm{CHCl}_{3} / \mathrm{HCOOH}$ solutions show a pronounced red-shift upon protonation of the heteroaromatic $\mathrm{N}$-atoms of the complex. This is not surprising as phenazine-derivatives are used as $\mathrm{pH}$-indicators (e.g. neutral red). As the effects of the spin state change on the intensity of the emission properties of [NiL1] and [NiL2] are extremely different and intriguing, lifetime measurements of the fluorescence were performed and are discussed further.

\section{Fluorescence lifetime analysis}

In addition to the steady-state fluorescence spectra shown in Fig. 5B and D for the complexes [NiL1] and [NiL2], lifetime measurements were performed on the same samples at $298 \mathrm{~K}$. The fluorescence decays were analysed using deconvolution fitting with double exponential decay functions. Fig. 6 compares selected fluorescence decays for complex solutions in trichloromethane and pyridine. It is clearly visible that the lifetime depends strongly on the type of solvent. In pyridine a significantly faster decay is observed as compared to trichloromethane. Table 4 summarises the results of the lifetime analysis for all measured solutions. The fluoresence decays 

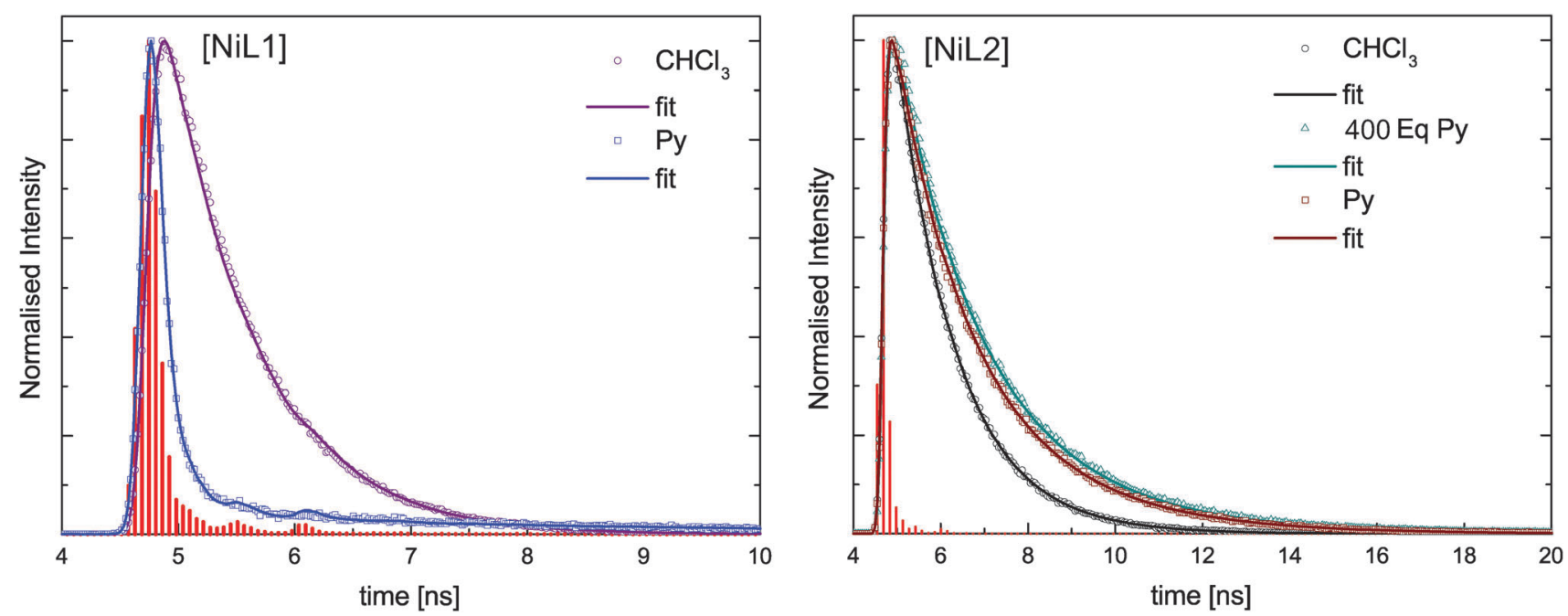

Fig. 6 Measured fluorescence decays for the nickel complexes. The instrument response function (IRF) is represented by the red vertical bars. The solid lines are deconvolution fits of the lifetime traces.

Table 4 Lifetime measurements data with the decay constant $\tau$ in ns. The error for the measured $\tau$ values are given in [\%]

\begin{tabular}{ll}
\hline Py equivalents & $\tau$ \\
\hline [NiL1] & \\
0 (trichloromethane solution) & $0.7[1 \%]$ \\
16 & $0.6[2 \%]$ \\
32 & $0.5[2 \%]$ \\
60 & $0.4[2 \%]$ \\
108 & $0.3[4 \%]$ \\
179 & $<0.2$ \\
230 & $<0.2$ \\
528 (pyridine solution) & $<0.2$ \\
[NiL2] & \\
0 (trichloromethane solution) & \\
20 & $1.3[<1 \%]$ \\
38 & $1.3[<1 \%]$ \\
73 & $1.6[<1 \%]$ \\
234 & $1.8[<1 \%]$ \\
302 & $2.0[<1 \%]$ \\
403 & $2.0[<1 \%]$ \\
470 & $1.9[<1 \%]$ \\
518 & $1.9[<1 \%]$ \\
644 & $1.8[<1 \%]$ \\
805 (pyridine solution) & $1.7[<1 \%]$ \\
& $1.7[<1 \%]$ \\
& $1.8[<1 \%]$ \\
& $1.7[<1 \%]$
\end{tabular}

for the complexes show monoexponential behavior for trichloromethane as solvent with relatively short lifetimes of $\tau=0.7 \mathrm{~ns}$ for [NiL1] and $\tau=1.3 \mathrm{~ns}$ for [NiL2]. For small equivalents of added pyridine the lifetime decreases in case of [NiL1] and the decays remain monoexponential. For higher amounts of pyridine, monoexponential decays could not be used to satisfyingly describe the decay profiles as a second longer lifetime component emerges. However this second contribution has very small amplitudes except for the highest amount of pyridine used. In the latter case the data analysis will be less reliable since the fast component provides lifetimes which are significantly smaller than the half width of the instrument response function. Therefore no conclusions will be drawn from the latter analysis result. As a general trend, it can be observed that the first lifetime component for [NiL1] systematically shortens with increasing amount of added pyridine.

For compound [NiL2], a different trend is observed upon addition of pyridine: the compound starts with a relatively longer lifetime of $\tau=1.3 \mathrm{~ns}$, which slightly increases upon addition of pyridine, reaching $1.8 \mathrm{~ns}$ in pure pyridine solution. For this complex all fluorescence decays were fitted with a monoexponential model and satisfying $\chi^{2}$ values were obtained.

\section{Discussion}

The complexes [ML1] and [ML2] were designed with the aim to favour possible non-radiative energy transfer between the heteroaromatic fluorophore, the donor, and the metal centre, the acceptor. Such design could give a control on the fluorescence properties of the fluorophore through changes of the spin state of the metal centre. As the distance between the donor and the acceptor plays a crucial role in the effectiveness of a non-radiative energy transfer, ${ }^{20}$ two different fluorophores with extended $\pi$-systems were used. The crystal structure of [NiL1] and [CuL1(EtOH)] $\mathbf{2 C H C l}_{\mathbf{3}}$ were successfully analysed by $\mathrm{X}$-ray diffraction. The obtained crystal structures present $\pi-\pi$ interactions in the packing between the complexes, as well as a hydrogen bond network in case of $[\mathbf{C u L 1}(\mathbf{E t O H})] \cdot \mathbf{2 C H C l}_{3}$. In the latter crystal structure, it is observed that the copper complex crystallizes in a square pyramidal geometry, although it is obtained as square planar complex in the bulk material. It was already observed in corresponding phenylene-derivatives copper(II) complexes that the metal centre is always trying to break its square planar symmetry, either by coordinating solvent molecules, or by sitting in a distorted coordination sphere. ${ }^{17}$ Unfortunately no crystals suitable for X-ray diffraction were obtained for the [ML2] samples, even when using vapourvapour or liquid-liquid slow diffusion setups. 
The spin state of the different complexes is usually due to their electronic configuration, with $S=\frac{1}{2}$ for the $3 \mathrm{~d}^{9} \mathrm{Cu}$ (II) complexes, and $S=0$ for the $3 \mathrm{~d}^{10} \mathrm{Zn}$ (II) complexes. In the case of the Ni(II) complexes, their spin state depends also on the geometry of the coordination sphere of the Ni(II) centre. In a square planar geometry, the nickel centre has a spin number of $S=0$, with all its electrons paired, however, upon coordination of pyridine on the axial position(s), the changes on the splitting of the d orbitals will induce a spin state change $(S=1)$, as described in the literature. ${ }^{8,16}$ The magnetic moment of the complex [NiL1] was determined with the Evans method: an effective magnetic moment $\mu_{\text {eff }}=0$ was measured in $\mathrm{CDCl}_{3}$ solution, in contrast to a $\mu_{\text {eff }}=2.78$ in pyridine- $\mathrm{d}_{5}$ solution, in good agreement with a theoretical value of $\mu_{\text {SO }}=2.83$ for $S=1$.

The investigation of the steady-state fluorescence of [ML1] compounds shows that the emission properties depend on the spin state of the metal centre. Indeed, diamagnetic metal centres, $\mathrm{Zn}$ (II) or Ni(II) in square planar geometry are fluorescent whereas for paramagnetic metal centres, $\mathrm{Cu}$ (II) or Ni(II) in square pyramidal/octahedral geometry, the fluorescence is quenched. The presence of unpaired electrons, and therefore partially filled orbitals, can give rise to an energy transfer between the fluorophore and the metal centre. A shortening of the lifetime of a given fluorophore is often observed when an energy transfer occurs, and this effect is observed for the complex [NiL1], as the emission lifetime gets shorter upon addition of pyridine, or in other words, upon coordination change induced spin state change (see Scheme 2). It has to be pointed out here that the sample [NiL1] exhibits a second contribution with a longer lifetime once a certain amount of pyridine equivalents is reached. The origin of this second component is not yet well understood and requires further investigations. The type of non-radiative energy transfer, whether it is a Förster or Dexter type cannot be pinpointed on the basis of the current investigation and requires further experiments or calculations.

The corresponding Zn(II) complex [ZnL1] displays a strong red-shift $(87 \mathrm{~nm})$ of the fluorescence upon coordination with pyridine. The same effect is observed for sample [ZnL2] but the red-shift is only in the order of $54 \mathrm{~nm}$, indicating that the metal centre has a reduced influence on the fluorescence properties of the bigger fluorophore.

The complex [NiL2] presents a very different behaviour than [NiL1] upon addition of pyridine. Instead of being quenched, its emission properties are actually intensifying upon the addition of the first equivalents of pyridine. After reaching a maximum, the emission band intensity is decreasing; however the sample in pure pyridine solution shows stronger fluorescence than the sample in pure trichloromethane solution. The opposite trend was observed for the complex [NiL1]. The lifetime measurements also present different results for [NiL2] than for [NiL1]. The lifetime of the emission is slightly increasing from $1.3 \mathrm{~ns}$ to $2.0 \mathrm{~ns}$ upon pyridine coordination. Then as the intensity of the emission peak is decreasing, the lifetime stays approximately constant ( $\tau=1.7 \mathrm{~ns}$ in pyridine solution).
Two hypotheses can be drawn about the big difference in the luminescence properties of the two nickel complexes. A difference in the nature of the transitions involved in the fluorophore could be the reason. It is described in literature that phenanthrene, and phenanthrene-derivatives like the ligand $\mathbf{H}_{2} \mathbf{L}$ 2, undergo forbidden transition, leading generally to longer lifetimes. ${ }^{21}$ Another reason could be a too long distance between the metal centre and the fluorophore, preventing any energy transfer. In this case, the effect observed on addition of pyridine would be of the same nature as solvatochromism. Finally, it is also possible that the first excited state of the fluorophore is at a lower energy than the first excited state of the metal centre, making the energy transfer impossible. Further investigations about the compound [NiL2], with varying temperature, or changing the coordinating solvent molecule i.e. for acetonitrile, are needed in order to understand the luminescence properties. Calculations of the different ground and excited states of the donor-acceptor pair would also give useful insights.

As complex [NiL1] showed an interesting coupling of the fluorescence properties with the spin state change, corresponding iron(II) complexes will be investigated in order to determine if such coupling is also obtained with a thermally induced spin crossover.

\section{Experimental section}

\section{Synthesis}

2,3-Diaminophenazine (1), 4,5-diamino- $N N^{\prime}$-ditoluene- $p$-sulphonyl$o$-phenylenediamine (2) and ethoxymethylene-ethylacetoacetate were synthesised as described in literature. ${ }^{22}$ Methanol, ethanol, trichloromethane and pyridine were of analytical grade and used without further purification. Nickel(II) acetate tetrahydrate (99\%, Fluka), copper(II) acetate monohydrate (99\%, Fluka), zinc(II) acetate dihydrate (97\%, Alfa Aesar), 9,10-phenanthrenequinone (95\%, Alfa Aesar) and sulphuric acid (97\%, Sigma Aldrich) were used without further purification. CHN analyses were measured with a Vario El III from Elementar Analysen-Systeme. Mass spectra were recorded with a Finnigan MAT 8500 with a data system MASPEC II. NMR spectra were measured with a Varian INOVA 300. Toluene was used as reference for the Evans method.

$6^{\prime}, 7^{\prime}$-Bis-(toluenesulfonamido)-quinoxaline- $\left[2^{\prime}, 3^{\prime}-d\right]-1,10$ phenanthrene (3). 4,5-Diamino- $N N^{\prime}$-ditoluene- $p$-sulphonyl-ophenylenediamine (2) (2.23 g) and 9,10-phenanthrenequinone $(1.05 \mathrm{~g})$ were dissolved in methanol $(50 \mathrm{~mL})$. The orange solution was refluxed during $1 \mathrm{~h}$, the colour of the solution changes progressively to yellow during the reflux. The solution is let to cool down to room temperature and a yellow powder precipitates. The yellow powder is filtered and washed with ice-cold methanol $(3 \times 20 \mathrm{~mL})$, and dried in vacuo to give the pure product 3 . Yield: $1.96 \mathrm{~g}(63 \%)$. MS (DEI-(+), $70 \mathrm{eV}) \mathrm{m} / \mathrm{z}(\%): 618$ (100) $\left(\mathrm{M}^{+}\right)$; elemental analysis calculated (found) for $\mathrm{C}_{34} \mathrm{H}_{36} \mathrm{~N}_{4} \mathrm{O}_{4} \mathrm{~S}_{2}$ (618.72 $\mathrm{g} \mathrm{mol}^{-1}$ ): C 66.00 (65.97), H 4.24 (4.05), N 9.06 (9.18). ${ }^{1} \mathrm{H}-\mathrm{NMR}$ (DMSO, $300 \mathrm{MHz}, \mathrm{ppm}) \delta=10.14$ (bs, $-\mathrm{NH}, 2 \mathrm{H}), 9.04$ (d, $J=9 \mathrm{~Hz}, \mathrm{Ar}-\mathrm{H}$, $4 \mathrm{H}), 8.64$ (d, J = 9 Hz, Ar-H, 4H), 7.79 (s, Ar-H, 2H), 7.76 (m, Ar-H, $8 \mathrm{H}), 2.34\left(\mathrm{~s},-\mathrm{CH}_{3}, 6 \mathrm{H}\right)$. 
$6^{\prime}, 7^{\prime}$-Diaminoquinoxaline- $\left[2^{\prime}, 3^{\prime}-d\right]$-1,10-phenanthrene (4). $6^{\prime}, 7^{\prime}$-Bis-(toluenesulfonamido)-quinoxaline-[2',3'- $\left.d\right]$-1,10-phenanthrene (3) (1.29 g) was dissolved in concentrated sulphuric acid $(10 \mathrm{~mL})$ and heated to $100{ }^{\circ} \mathrm{C}$ during $4 \mathrm{~h}$. A change of colour of the solution from yellow to purple was observed. The solution was cooled down to $0{ }^{\circ} \mathrm{C}$ and $50 \mathrm{~mL} \mathrm{H}_{2} \mathrm{O}$ was added dropwise to the solution, and a brown powder precipitates from the solution. The brown powder was filtered and washed with $10 \mathrm{~mL} \mathrm{H}_{2} \mathrm{O}$, then suspended in $20 \mathrm{~mL} \mathrm{H}_{2} \mathrm{O}$. Ammonium hydroxide solution (25\%) was added to the suspension under vigorous stirring until its $\mathrm{pH}$ reaches 8 . The solid turned redbrown during the addition, was then filtered, washed with $\mathrm{H}_{2} \mathrm{O}$ $(2 \times 5 \mathrm{~mL})$, and dried in vacuo to give the pure product 4 . Yield: $0.47 \mathrm{~g}$ (72\%). MS (DEI-(+), $70 \mathrm{eV}) \mathrm{m} / \mathrm{z}(\%): 310$ (100) $\left(\mathrm{M}^{+}\right)$; elemental analysis calculated (found) for $\mathrm{C}_{20} \mathrm{H}_{14} \mathrm{~N}_{4}\left(310.35 \mathrm{~g} \mathrm{~mol}^{-1}\right)$ : C 77.40 (77.24), H 4.55 (4.15), N 18.05 (18.25). ${ }^{1} \mathrm{H}-\mathrm{NMR}$ (DMSO, $300 \mathrm{MHz}, \mathrm{ppm}) \delta=9.17(\mathrm{~m}, \mathrm{Ar}-\mathrm{H}, 2 \mathrm{H}), 8.74(\mathrm{~m}, \mathrm{Ar}-\mathrm{H}, 2 \mathrm{H}), 7.73$ (m, Ar-H, 4H), 7.12 (s, Ar-H, 2H), 6.11 (bs, - $\left.\mathrm{NH}_{2}, 4 \mathrm{H}\right)$.

$\mathbf{H}_{2} \mathbf{L 1}$ : 2,3-diaminophenazine (1) (0.5 g) and ethoxymethyleneethylacetoacetate $(0.93 \mathrm{~g})$ were dissolved in $20 \mathrm{~mL}$ ethanol. The solution was refluxed during 1 hour, and a brownish yellow powder precipitated upon reflux. The brownish yellow powder was filtered, washed with $5 \mathrm{~mL}$ cold ethanol. Recrystallization from ethanol gives the pure product $\mathbf{H}_{2} \mathbf{L} \mathbf{1}$ as brownish yellow crystals. Yield: $0.48 \mathrm{~g}$ (42\%). MS (DEI-(+), $70 \mathrm{eV}) \mathrm{m} / \mathrm{z}$ (\%): 490 (100) $\left(\mathrm{M}^{+}\right)$; elemental analysis calculated (found) for $\mathrm{C}_{34} \mathrm{H}_{30} \mathrm{~N}_{4} \mathrm{O}_{6}$ (490.51 $\mathrm{g} \mathrm{mol}^{-1}$ ): C 63.66 (66.30), H 5.34 (5.15), N 11.42 (11.65). ${ }^{1} \mathrm{H}-\mathrm{NMR}$ (DMSO, $\left.300 \mathrm{MHz}, \mathrm{ppm}\right) \delta=12.67$ (d, $J=12 \mathrm{~Hz},-\mathrm{NH}$, $2 \mathrm{H}), 8.52(\mathrm{~d}, J=12 \mathrm{~Hz},=\mathrm{C}-\mathrm{H}, 2 \mathrm{H}), 8.25(\mathrm{~s}, \mathrm{Ar}-\mathrm{H}, 2 \mathrm{H}), 8.18$ $\left(\mathrm{dd}, J^{3}=6 \mathrm{~Hz}, J^{4}=3 \mathrm{~Hz}, \mathrm{Ar}-\mathrm{H}, 2 \mathrm{H}\right), 7.94\left(\mathrm{dd}, J^{3}=6 \mathrm{~Hz}, J^{4}=3 \mathrm{~Hz}\right.$, $\mathrm{Ar}-\mathrm{H}, 2 \mathrm{H}$ ), 4.18 (qua, $\left.J=7.5 \mathrm{~Hz},-\mathrm{CH}_{2}, 4 \mathrm{H}\right), 2.49\left(\mathrm{~s},-\mathrm{CH}_{3}, 6 \mathrm{H}\right.$ ), $1.32\left(\mathrm{t}, J=7.5 \mathrm{~Hz},-\mathrm{CH}_{3}, 6 \mathrm{H}\right)$.

$\mathbf{H}_{2} \mathbf{L} 2: 6^{\prime}, 7^{\prime}$-diaminoquinoxaline- $\left[2^{\prime}, 3^{\prime}-d\right]-1,10$-phenanthrene (4) (0.17 g) and ethoxymethyleneethylacetoacetate ( $0.26 \mathrm{~g})$ were dissolved in $10 \mathrm{~mL}$ ethanol. The solution was refluxed during 1 hour, and a yellow powder precipitated upon reflux. The yellow powder was filtered, washed with $5 \mathrm{~mL}$ cold ethanol. Recrystallization from ethanol gives the pure product $\mathbf{H}_{2} \mathbf{L} 2$ as yellow crystals. Yield: $0.24 \mathrm{~g}$ (74\%). MS (DEI-(+), $70 \mathrm{eV}) \mathrm{m} / \mathrm{z}(\%)$ : 590 (100) $\left(\mathrm{M}^{+}\right)$; elemental analysis calculated (found) for $\mathrm{C}_{34} \mathrm{H}_{30} \mathrm{~N}_{4} \mathrm{O}_{6}\left(590.63 \mathrm{~g} \mathrm{~mol}^{-1}\right)$ : $\mathrm{C} 69.14$ (69.30), H 5.12 (5.15), $\mathrm{N}$ 9.49 (9.65). ${ }^{1} \mathrm{H}-\mathrm{NMR}$ (DMSO, $\left.300 \mathrm{MHz}, \mathrm{ppm}\right) \delta=12.59$ (d, $J=12 \mathrm{~Hz}$, -NH, 2H), 9.13 (m, Ar-H, 2H), 8.69 (m, Ar-H, 2H), 8.65 (d, J=12 Hz, $=\mathrm{C}-\mathrm{H}, 2 \mathrm{H}$ ), $7.68(\mathrm{~m}, \mathrm{Ar}-\mathrm{H}, 4 \mathrm{H}), 7.10$ (s, Ar-H, 2H), 4.17 (qua, $J=$ $\left.7.5 \mathrm{~Hz},-\mathrm{CH}_{2}, 4 \mathrm{H}\right), 2.47\left(\mathrm{~s},-\mathrm{CH}_{3}, 6 \mathrm{H}\right), 1.33\left(\mathrm{t}, J=7.5 \mathrm{~Hz},-\mathrm{CH}_{3}, 6 \mathrm{H}\right)$.

[NiL1]: $\mathbf{H}_{2} \mathbf{L 1}(0.2 \mathrm{~g})$ and nickel(II) acetate tetrahydrate $(0.12 \mathrm{~g})$ were dissolved in $20 \mathrm{~mL}$ ethanol. The solution was refluxed during 1 hour, and an orange powder precipitated upon reflux. The orange powder was filtered, washed with $5 \mathrm{~mL}$ cold ethanol. Recrystallization from ethanol gives the pure complex as orange powder. Yield: $0.20 \mathrm{~g}$ (88\%). MS (DEI-(+), $70 \mathrm{eV}) \mathrm{m} / \mathrm{z}$ (\%): $546(100)\left(\mathbf{M}^{+}\right)$; elemental analysis calculated (found) for $\mathrm{C}_{26} \mathrm{H}_{24} \mathrm{~N}_{4} \mathrm{NiO}_{6}\left(547.19 \mathrm{~g} \mathrm{~mol}^{-1}\right.$ ): C 57.07 (56.98), H 4.42 (4.15), N 10.24 (10.42).

[CUL1]: $\mathbf{H}_{2} \mathbf{L 1}(0.2 \mathrm{~g})$ and copper(II) acetate monohydrate $(0.10 \mathrm{~g})$ were dissolved in $20 \mathrm{~mL}$ ethanol. The solution was refluxed during 1 hour, and a brown powder precipitated upon reflux. The brown powder was filtered, washed with $5 \mathrm{~mL}$ cold ethanol. Recrystallization from ethanol gives the pure complex as brown powder. Yield: $0.21 \mathrm{~g}(91 \%)$. MS (DEI- $(+), 70 \mathrm{eV}) \mathrm{m} / \mathrm{z}$ (\%): 551 (100) $\left(\mathrm{M}^{+}\right)$; elemental analysis calculated (found) for $\mathrm{C}_{26} \mathrm{H}_{24} \mathrm{~N}_{4} \mathrm{CuO}_{6}\left(552.04 \mathrm{~g} \mathrm{~mol}^{-1}\right.$ ): $\mathrm{C} 56.57$ (56.48), H 4.38 (4.23), N 10.15 (10.05).

[ZnL1]: $\mathbf{H}_{2} \mathbf{L 1}(0.2 \mathrm{~g})$ and zinc(II) acetate dihydrate $(0.11 \mathrm{~g})$ were dissolved in $20 \mathrm{~mL}$ ethanol. The solution was refluxed during 1 hour, and a red powder precipitated upon reflux. The red powder was filtered, washed with $5 \mathrm{~mL}$ cold ethanol. Recrystallization from ethanol gives the pure complex as red powder. Yield: $0.18 \mathrm{~g}$ (79\%). MS (DEI-(+), $70 \mathrm{eV}) \mathrm{m} / \mathrm{z}(\%)$ : 552 (100) $\left(\mathrm{M}^{+}\right)$; elemental analysis calculated (found) for $\mathrm{C}_{26} \mathrm{H}_{24} \mathrm{~N}_{4} \mathrm{O}_{6} \mathrm{Zn}$ (553.87 $\left.\mathrm{g} \mathrm{mol}^{-1}\right)$ : $\mathrm{C} \quad 56.38$ (56.29), $\mathrm{H} \quad 4.37$ (4.43), N 10.12 (10.13).

[NiL2]: $\mathbf{H}_{2} \mathbf{L 2}(0.2 \mathrm{~g})$ and nickel(II) acetate tetrahydrate $(0.10 \mathrm{~g})$ were dissolved in $20 \mathrm{~mL}$ ethanol. The solution was refluxed during 1 hour, and an yellow powder precipitated upon reflux. The yellow powder was filtered, washed with $5 \mathrm{~mL}$ cold ethanol. Recrystallization from ethanol gives the pure complex as yellow powder. Yield: $0.17 \mathrm{~g}$ (76\%). MS (DEI-(+), $70 \mathrm{eV}) \mathrm{m} / \mathrm{z}$ (\%): 646 (100) $\left(\mathrm{M}^{+}\right)$; elemental analysis calculated (found) for $\mathrm{C}_{34} \mathrm{H}_{28} \mathrm{~N}_{4} \mathrm{NiO}_{6}\left(647.30 \mathrm{~g} \mathrm{~mol}^{-1}\right)$ : $\mathrm{C} 63.09$ (63.16), H 4.36 (4.45), N 9.07 (9.05).

[CuL2]: $\mathbf{H}_{2} \mathbf{L} 2(0.2 \mathrm{~g})$ and copper(II) acetate monohydrate $(0.08 \mathrm{~g})$ were dissolved in $20 \mathrm{~mL}$ ethanol. The solution was refluxed during 1 hour, and a brown powder precipitated upon reflux. The brown powder was filtered, washed with $5 \mathrm{~mL}$ cold ethanol. Recrystallization from ethanol gives the pure complex as brown powder. Yield: $0.19 \mathrm{~g}$ (86\%). MS (DEI- $(+), 70 \mathrm{eV}) \mathrm{m} / \mathrm{z}$ (\%): 651 (100) $\left(\mathrm{M}^{+}\right)$; elemental analysis calculated (found) for $\mathrm{C}_{34} \mathrm{H}_{28} \mathrm{~N}_{4} \mathrm{CuO}_{6}\left(652.16 \mathrm{~g} \mathrm{~mol}^{-1}\right.$ ): $\mathrm{C} 62.62$ (62.58), H 4.33 (4.18), N 8.59 (8.65).

[ZnL2]: $\mathbf{H}_{2} \mathbf{L} 2(0.2 \mathrm{~g})$ and zinc(II) acetate dihydrate (0.06 g) were dissolved in $20 \mathrm{~mL}$ ethanol. The solution was refluxed during 1 hour, and an orange powder precipitated upon reflux. The orange powder was filtered, washed with $5 \mathrm{~mL}$ cold ethanol. Recrystallization from ethanol gives the pure complex as orange powder. Yield: $0.12 \mathrm{~g}(82 \%)$. MS (DEI-(+), $70 \mathrm{eV}) \mathrm{m} / \mathrm{z}$ (\%): 652 (100) $\left(\mathrm{M}^{+}\right)$; elemental analysis calculated (found) for $\mathrm{C}_{26} \mathrm{H}_{24} \mathrm{~N}_{4} \mathrm{O}_{6} \mathrm{Zn}$ (653.99 $\mathrm{g} \mathrm{mol}^{-1}$ ): $\mathrm{C} 62.44$ (62.32), H 4.32 (4.27), N 8.57 (8.51).

\section{$\mathrm{X}$-ray structure analysis}

The X-ray analysis of the [NiL1] and $[\mathbf{C u L 1}(\mathbf{E t O H})] \cdot \mathbf{2 C H C l}_{\mathbf{3}}$ complexes was performed with a Stoe StadiVari diffractometer using graphite-monochromated $\mathrm{MoK} \alpha$ radiation. The data were corrected for Lorentz and polarization effects. The structures were solved by direct methods (SIR-97) ${ }^{23}$ and refined by fullmatrix least-square techniques against Fo2-Fc2 (SHELXL-97). ${ }^{24}$ All hydrogen atoms were calculated in idealised positions with fixed displacement parameters. ORTEP-III ${ }^{25}$ was used for the structure representation, SCHAKAL- $99^{26}$ to illustrate molecule packing. CCDC 1055605 and 1055606. 
Powder diffractograms were measured with a STOE StadiP Powder Diffractometer (STOE, Darmstadt) using $\mathrm{Cu}$ [Ka1] radiation with a Ge Monochromator, and a Mythen $1 \mathrm{~K}$ Stripdetector in transmission geometry.

\section{Optical measurements}

Absorbance spectra were obtained using a Agilent UV-vis spectrophotometer 8453 (Agilent Technologies, USA) operating in a spectral range of 190-1100 $\mathrm{nm}$. The spectra were measured at $298 \mathrm{~K}$ in quartz cells with $1 \mathrm{~cm}$ lightpath (Hellma, Germany). Fluorescence measurements were performed with a FLS980 (Edinburgh Instruments, UK) fluorescence spectrometer equipped with double monochromators (1800 grooves per $\mathrm{mm}$ ) in excitation and emission. A Xe lamp (360 W) was used as excitation source for steady-state fluorescence measurements. Time-resolved measurements were performed with a pulsed supercontinuum fiber laser (WhiteLase SC-400, Fianium, UK) with a pulse width $<10 \mathrm{ps}$ and a repetition rate of $5 \mathrm{MHz}$. Emission from the sample was collected at an angle of $90^{\circ}$ with respect to the excitation path. The emitted beam was focused onto a single photon counting photomultiplier (R928P, Hamamatsu, Japan) or a microchannel plate photomultiplier (MCP-PMT) for steady-state and lifetime measurements respectively. All spectra were measured at $298 \mathrm{~K}$ in quartz cells (Hellma, Germany) with $1 \mathrm{~cm}$ lightpath. The excitation wavelength and time range for lifetime measurements were selected according to the sample requirements. The time-resolved fluorescence decays were analysed by deconvolution fits accounting for the instrument response function (IRF) obtained from a Rayleigh scatterer.

\section{Conclusion}

Two new Schiff base-like ligands bearing a fluorophore were synthesised and successfully used for complexation of $\mathrm{Ni}$ (II), $\mathrm{Cu}$ (II) and $\mathrm{Zn}$ (II). While for the $\mathrm{Cu}$ (II) complexes the fluorescence is quenched, the $\mathrm{Zn}$ (II) and $\mathrm{Ni}$ (II) complexes retain the photoluminescent properties. We have shown that the addition of pyridine induces a change in the geometry of the complex, and consequently a change of the spin state. While the $\mathrm{Zn}$ (II) complexes only display a red-shift of the emission upon coordination, the nickel(II) complexes exhibit a more complex behaviour. The sample [NiL1] showed a quenching of its fluorescence correlated to a coordination change-induced spin state change, with a dramatic decrease of the intensity and lifetime of the emission band. This is in agreement with the appearance of non-radiative energy transfer between the fluorophore and the Ni(II) centre in its $S=1$ paramagnetic state. The sample [NiL2], bearing a more extended phenanthrene-based fluorophore, displays a more complex behaviour upon coordination of pyridine which requires further investigation. This will be addressed in a future work. Corresponding iron(II) complexes will also be investigated with regard to possible correlation effects between fluorescence and thermally induced spin crossover.

\section{Acknowledgements}

Financial supports from the German Science foundation (SFB840) and the University of Bayreuth are acknowledged. Mathias Karg and Kristina G. Wagner acknowledge financial support from the German Research Foundation (DFG) via the Emmy-Noether Programme. We thank F. Puchtler (University of Bayreuth) for the collection of powder diffraction data.

\section{Notes and references}

1 (a) Spin-Crossover Materials, ed. M. A. Halcrow, John Wiley \& Sons Ltd, Chichester, 2013; (b) Spin Crossover in Transition Metal Compounds I-III, ed. P. Gütlich and H. Goodwin, Springer, Berlin/Heidelberg, 2004, pp. 233-235; (c) P. Gütlich, A. B. Gaspar and Y. Garcia, Beilstein J. Org. Chem., 2013, 9, 342-391; (d) A. B. Gaspar and M. Seredyuk, Coord. Chem. Rev., 2014, 268, 41-58; (e) E. Coronado and G. Mínguez Espallargas, Chem. Soc. Rev., 2013, 42, 1525; $(f)$ P. D. Southon, L. Liu, E. A. Fellows, D. J. Price, G. J. Halder, K. W. Chapman, B. Moubaraki, K. S. Murray, J.-F. Létard and C. J. Kepert, J. Am. Chem. Soc., 2009, 131, 10998-11009.

2 (a) J. Linares, E. Codjovi and Y. Garcia, Sensors, 2012, 12, 4479-4492; (b) A. Dei, Angew. Chem., Int. Ed. Engl., 2005, 44, 1160-1163; (c) C. Edder, C. Piguet, J.-C. G. Bünzli and G. Hopfgartner, Chem. - Eur. J., 2001, 7, 3014-3024.

3 P. N. Martinho, C. Rajnak and M. Ruben, in Spin-Crossover Materials, ed. M. A. Halcrow, John Wiley \& Sons Ltd, Chichester, 2013, pp. 375-404.

4 B. Weber, W. Bauer and J. Obel, Angew. Chem., Int. Ed., 2008, 47, 10098-10101.

5 (a) J. Larionova, L. Salmon, Y. Guari, A. Tokarev, K. Molvinger, G. Molnár and A. Bousseksou, Angew. Chem., Int. Ed., 2008, 47, 8236-8240; (b) E. Coronado, J. R. GalánMascarós, M. Monrabal-Capilla, J. García-Martínez and P. Pardo-Ibáñez, Adv. Mater., 2007, 19, 1359-1361.

6 (a) J.-F. Letard, J. Mater. Chem., 2006, 16, 2550-2559; (b) S. Bonhommeau, G. Molnár, A. Galet, A. Zwick, J.-A. Real, J. J. McGarvey and A. Bousseksou, Angew. Chem., Int. Ed., 2005, 44, 4069-4073.

7 B. Weber, in Spin-Crossover Materials, ed. M. A. Halcrow, John Wiley \& Sons Ltd, Chichester, 2013, pp. 55-76.

8 (a) S. Venkataramani, U. Jana, M. Dommaschk, F. D. Sonnichsen, F. Tuczek and R. Herges, Science, 2011, 331, 445-448; (b) S. Thies, H. Sell, C. Schütt, C. Bornholdt, C. Näther, F. Tuczek and R. Herges, J. Am. Chem. Soc., 2011, 133, 16243-16250; (c) S. Thies, C. Bornholdt, F. Köhler, F. D. Sönnichsen, C. Näther, F. Tuczek and R. Herges, Chem. - Eur. J., 2010, 16, 10074-10083; (d) D. Achey and G. J. Meyer, Inorg. Chem., 2013, 52, 9574-9582; (e) C. J. Ballhausen and A. D. Liehr, J. Am. Chem. Soc., 1959, 81, 538-542.

9 (a) M. Matsuda, H. Isozaki and H. Tajima, Chem. Lett., 2008, 37, 374-375; (b) M. Matsuda, K. Kiyoshima, R. Uchida, N. Kinoshita and H. Tajima, Thin Solid Films, 2013, 531, 
451-453; (c) M. Matsuda, H. Isozaki and H. Tajima, Thin Solid Films, 2008, 517, 1465-1467.

10 L. Salmon, G. Molnár, D. Zitouni, C. Quintero, C. Bergaud, J.-C. Micheau and A. Bousseksou, J. Mater. Chem., 2010, 20, 5499.

11 C.-F. Wang, R.-F. Li, X.-Y. Chen, R.-J. Wei, L.-S. Zheng and J. Tao, Angew. Chem., Int. Ed., 2015, 54, 1574-1577.

12 H. Matsukizono, K. Kuroiwa and N. Kimizuka, Chem. Lett., 2008, 37, 446-447.

13 Y. Garcia, F. Robert, A. D. Naik, G. Zhou, B. Tinant, K. Robeyns, S. Michotte and L. Piraux, J. Am. Chem. Soc., 2011, 133, 15850-15853.

14 (a) A. Santoro, L. J. Kershaw Cook, R. Kulmaczewski, S. A. Barrett, O. Cespedes and M. A. Halcrow, Inorg. Chem., 2015, 54, 682-693; (b) M. Hasegawa, F. Renz, T. Hara, Y. Kikuchi, Y. Fukuda, J. Okubo, T. Hoshi and W. Linert, Chem. Phys., 2002, 277, 21-30; (c) L. J. Kershaw Cook and M. A. Halcrow, Polyhedron, 2015, 87, 91-97.

15 M. Engeser, L. Fabbrizzi, M. Licchelli and D. Sacchi, Chem. Commun., 1999, 1191-1192.

16 L. Wolf and E.-G. Jäger, Z. Anorg. Allg. Chem., 1966, 346, 76-91.

17 C. Lochenie, S. Schlamp, A. P. Railliet, K. Robeyns, B. Weber and Y. Garcia, CrystEngComm, 2014, 16, 6213.

18 W. Bauer, T. Ossiander and B. Weber, Z. Naturforsch., B: J. Chem. Sci., 2010, 323-328.
19 (a) N. Chopin, M. Médebielle, O. Maury, G. Novitchi and G. Pilet, Eur. J. Inorg. Chem., 2014, 6185-6195; (b) H. S. Jung, P. S. Kwon, J. W. Lee, J. I. Kim, C. S. Hong, J. W. Kim, S. Yan, J. Y. Lee, J. H. Lee, T. Joo and J. S. Kim, J. Am. Chem. Soc., 2009, 131, 2008-2012.

20 Z. Liu, W. He and Z. Guo, Chem. Soc. Rev., 2013, 42, 1568-1600.

21 B. Valeur and M. N. Berberan-Santos, Molecular Fluorescence. Principles and applications, Wiley-VCH, Weinheim, 2nd edn, 2013.

22 (a) N. P. Loveless, K. C. Brown and R. H. Horrocks, J. Org. Chem., 1981, 46, 1182-1185; (b) G. W. H. Cheeseman, J. Chem. Soc., 1962, 1170; (c) X. Shang, X. Li, N. Xi, Y. Zhai, J. Zhang and X. Xu, Sens. Actuators, B, 2011, 160, 1112-1119; (d) L. Claisen, Justus Liebigs Ann. Chem., 1897, 297, 1-98.

23 A. Altomare, M. C. Burla, M. Camalli, G. L. Cascarano, C. Giacovazzo, A. Guagliardi, A. G. G. Moliterni, G. Polidori and R. Spagna, J. Appl. Crystallogr., 1999, 32, 115-119.

24 G. Sheldrick, Acta Crystallogr., Sect. A: Found. Crystallogr., 2008, 64, 112-122.

25 (a) C. K. Johnson and M. N. Burnett, ORTEP-III, Oak-Ridge National Laboratory, Oak-Ridge, TN, 1996; (b) L. Farrugia, J. Appl. Crystallogr., 1997, 30, 565.

26 E. Keller, Schakal-99, University of Freiburg, Freiburg, Germany, 1999. 